DOI: https://doi.org/10.3126/tgb.v6i0.26168

\title{
Impact of Pesticide and Fertilizer on Human Health: A Case Study in Godawari Area, Lalitpur, Nepal
}

\author{
Nirmala Basnet ${ }^{1}$ Chabbi Lal Chidi ${ }^{2}$
}

\begin{abstract}
Different types of pesticides and chemical fertilizers are in use in Nepal which is harmful for human health. These chemical fertilizers and pesticides are beyond the limitation and restriction. However, scientific study is very limited in Nepal. So, this study aims to assess the situation of use and protection system of pesticides users. This study is based on field level data of Godawari area of Lalitpur district. In Godawari area, Urea and DAP are mostly used for cereal crops and potash is mostly for vegetables. Pesticides and fertilizers are mostly used in vegetable farming but protection system during the use of pesticides and fertilizer is not satisfactory. So, these chemicals have been negatively affecting on the health of the local farmers.
\end{abstract}

Key Words: Pesticides, fertilizer, human health, protection system, negative effect

\section{Introduction}

More than 50 years ago, when increased food production was seen to be the most urgent need, a high priority was rightly given world-wide to the eradication of losses in both production and storage that were to weeds, insects and diseases transmitted by insects. Chemists at the time were discovering how to synthesize a range of organic compounds that were lethal to insects and which heralded a revolution in pest control. Use of pesticides cause many hazards in the health of human beings (Sabur and Molla 2001). Several types of pesticides are in use which was recorded after 1940s in the United States and around the world. Pesticides have made a great impact on human health. However, the use of pesticides is increasing rapidly during the last four decades (Kumar et al. 2012). It is now known that many if not most of the compounds used in pesticides are carcinogenic, they are lethal to birds and animals including the natural predators of the insects that are to be controlled (Tribe, 1994). Agrochemical used as pesticides and fertilizers are being a

\footnotetext{
${ }^{1} \mathrm{PhD}$ Scholar, Central Department of Geography, Tribhuvan University. Corresponding email: nirmifordrink@gmail.com

2 Lecturer, Central Department of Geography, Tribhuvan University.
} 
serious concern mainly in the commercial pockets' areas of agricultural production, where farmers are suffering from environmental pollution. Incidence of poisoning is also increasing due to intentional, incidental and occupational exposure. Toxic and environmentally persistent chemicals are being used as pesticides. Many studies showed that the chemical pollution of the environment has long term effects on human life (Sharma et al. 2012). Agrochemicals are powerful weapons in the developing countries to enhance the agriculture productivity including Nepal. However, those agrochemicals are causing serious hazards (Bhandari 2014). Generally, many parts of India, farmers do not use the safety masks, gloves and other protective gears during the spraying of pesticides which results into the access of pesticides in the blood stream through inhalation and dermal exposure which can adversely affect their eyes, skin and the respiratory system. The study shows relationship between the extent of pesticide used and signs and symptoms of illnesses due to exposure among spray farmers (Sharma and Singhvi 2017). Similarly, in Nepal too many different types of pesticides have been in use. Several reports of human sickness due to food poisoning have been reported.

Health workers have reported that food poisoning in Nepal is being due to the use of pesticides and chemical fertilizer in crops. It is also reported that the use of these chemical fertilizers and pesticides are beyond the limitation and restriction. Pesticides are not as extensively used in Nepal as in other Asian countries in terms of the ratio of active ingredients used per hector of cropland. Thus, hazards caused by pesticides application in Nepal are not only due to overuse of pesticides but also more due to misuse of pesticides. The quality of pesticides used is increasing in Nepal without any study about the proper use and its effect on environment, ecosystem and health of the living beings (Ghimire \& Khatiwada, 2001).

Safely and healthy use of agrochemicals is one of the primary concerns of international organizations because some agrochemicals such as pesticides are extremely hazardous to the health of workers and the general public. The current issue of hazard posed by pesticides to human health and the environment has raised concerns. Production of better alternative to reduce pesticide formulations is an answer to this apocalyptic condition. Increasing urbanization in Nepal has increased higher demand of green vegetables and agriculture product including food crops in and around the city area. Fertilizer and pesticides are used to increase production and protection of crops. Most farmers are unaware about the negative aspect of this agrochemical product and some policy implantation in Nepal is very weak. So, there are frequent message the result of health problems related due to agrochemical product. Nevertheless, neither concerned government agencies nor 
private sectors are serious. Therefore, this study aims to explore and analyze the situation of use of agrochemical product such as chemical fertilizer and pesticides and precaution used in agriculture production in Godawari area of Kathmandu Valley.

\section{Methodology}

\section{Study area}

Godawari is a well-known place of Kathmandu valley which is located at the south margin of valley flat land and lap of Phulchoki Mountain which is the highest peak of the surrounding mountains of Kathmandu valley. Due to its location and one of the best botanical gardens, picnic spots, it is well-known to the most of the people of Kathmandu valley and Nepalese people as well. It is at $9 \mathrm{~km}$ south from the Lagankhel of Lalitpur city. Godawari is located at an elevation of 1500 feet above sea level. Thaiba and Godamchour to the north and Badikhel VDC to the south. Topographically gently sloping toward north surrounded by steep hill sides of the valley is general surface feature in the study area.

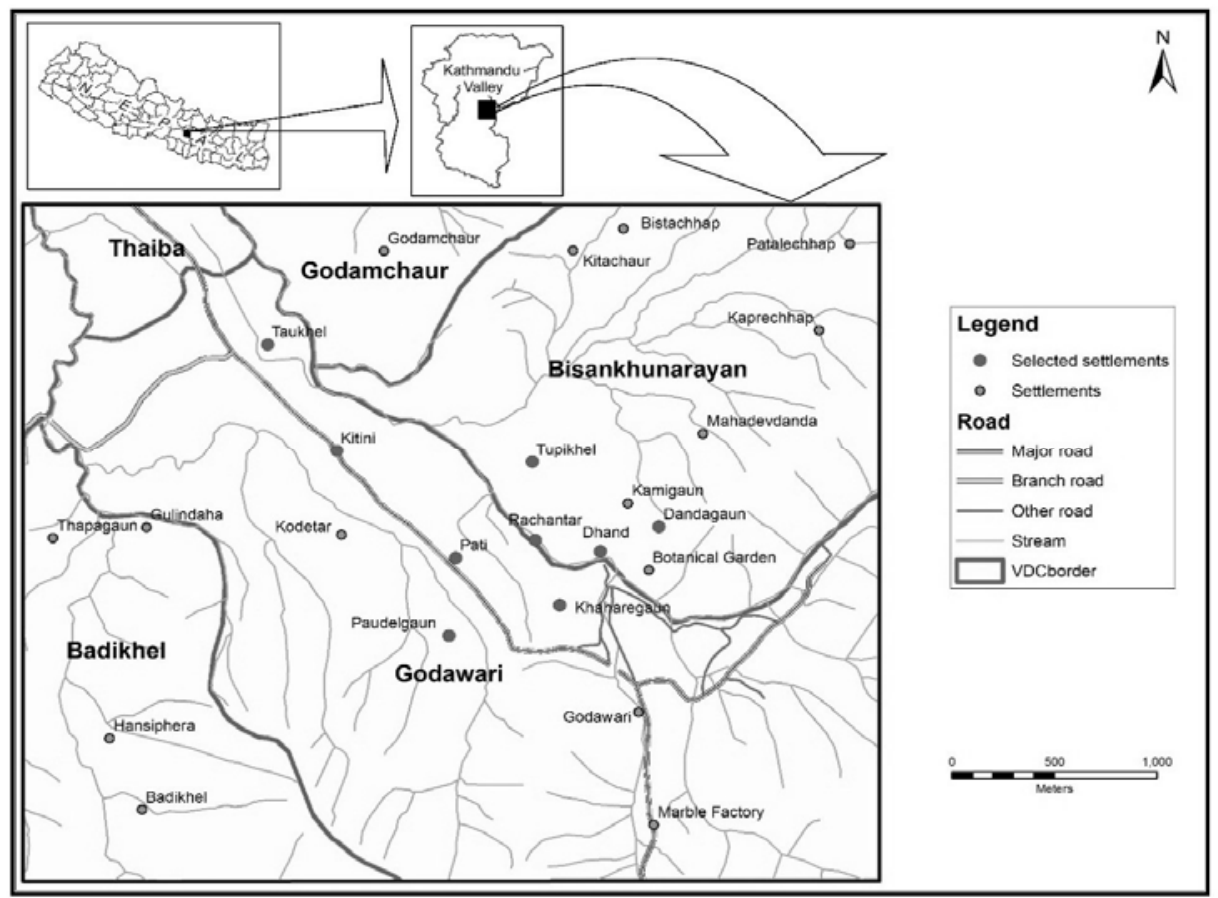

Figure 1: Study area

The study area is linked with road from Kathmandu and Lalitpur city by Lagankhel-Godawari road. Some settlements of Godawari and Bisankhunarayan 
VDCs have been selected as study area which is nearby along the LagankhelGodawari road. Households were selected from ten settlements of two VDCs i.e. six settlements from Godawari and four settlements from Bisankhunarayan VDC. Those settlements are Taukhel, Kitini, Kodetar, Pati, Paudelgaun and Khaharegaun from Godawari VDC and Tupikhet, Ratanchour, Dhand and Dandagaun vellages from

Bisankhunarayan VDC. Majority of the land is covered with cultivated land and is located at $27^{\circ} 34^{\prime} 24^{\prime \prime}$ North to $27^{\circ} 22^{\prime} 12^{\prime \prime}$ North and $85^{\circ} 22^{\prime} 12^{\prime \prime}$ to $85^{\circ} 48^{\prime} 36^{\prime \prime}$ East. $20 \%$ of the land is sloppy while $80 \%$ of the land is flat. The area covered is 7.45 square $\mathrm{Km} .390$ hectares of land is good for agriculture and rest all forested area. This VDC consists of three landform units; gently sloping valley floor, moderately steep hill slope and very steep hills. The distribution of area in terms of altitude is not uniform. The area decreases with increasing altitude. Most of the areas are valley floor, which is more or less flat topography.

\section{Tools and techniques}

Godawori area of Kathmandu valley was selected for primary data collection area which is accessible to visit settlements. Selected settlements are adjoining and accessible village location from where commercial crops such as vegetables are easily supplied to Kathmandu city. There are many farmers who produce vegetables as a commercial crop and cereal crops for home consumption. Some specific settlements were selected for field level data collection from the study area. Five settlements were selected from Godawari VDC and four settlements were from Bisankhunarayen VDC. Taukhel, Kitini, Pati, Paudelgaun and Khahare gaun were from Godawari VDC and Tupikhel, Ratanchaur, Dhand and Dandagaun were from Bisankhunarayan VDC. Kitini and Pati settlements are along the Lagankhel Godawari road and Paudelgaun is west of this road. Other settlements are eastern side of the road. However, all of these settlements are easily accessible from Kathamnadu city. Thirty households from these settlements were selected purposively to get required information. The selected settlements are under wards seven, eight and nine of Bisankhunarayen VDC and wards one, three, five and six of Godawari VDC.

Primary data were collected through questionnaire and interview methods. Thirty household questionnaires were filled from the selected households of different settlements. In addition to household questionnaires, observation and informal discussion were also made during the field study. Field notes were also prepared to record field level information through informal discussion and observation. For 
household survey a questionnaire was developed containing 14 different questions. The questionnaire was filled by interview with household member who can answer the questions and household information. During field survey those informants were both male and female but age was above 25 years. Photos of vegetable production, cereal crops and pesticide use have been taken during field survey. Topographical maps of 1:25000 scale was collected from the Survey Department, Government of Nepal which was the base map for location and general topographical information of the study area. Additionally, image of Google earth and other descriptive information were also collected. Some information was retrieved from the internet and the central library of Tribhuvan University. Temperature and rainfall data were collected from the Department of Hydrology and Meteorology of Government of Nepal. Climatic data were taken derived from Godawari Meteorological station as a representative climatic situation of the study area.

Firstly, secondary information such as maps and images were used to identify the selected study area and preparing location map. Information collected through observation and informal discussions were listed according to the requirements of research objectives. Household level information was tabulated in excel sheet. These data were tabulated on the basis of items such as crops, fertilizer, pesticides etc. Frequency table of households and area of the cultivated land for different crops have been generated. Table of fertilizers and pesticides used for different crops, protection system used by farmers during the use of pesticides have been developed. Tabulated frequency and area cultivated were converted into percentage to compare the comparative proportion of different items. Tabulated and calculated values have been presented using suitable diagrams. Analysis mainly focuses on the objectives of the study. The main aspect of analysis is how many farmers use different types of fertilizer and pesticides for which crops, what protection system are using by farmers during the use of pesticides for crops and intensity of effect of pesticides on health of farmers. However, the effect of human health is being only qualitative description.

\section{Results and discussion}

\section{Agriculture crops}

Paddy was grown in 61.81 ropani of land which is $31.40 \%$ of the total cultivation in 2014. Beans are grown in about 4.06 ropni of land which is $2.08 \%$ of the total cultivation under study. Wheat is grown in 43.50 ropani i.e. $22.31 \%$ of the total cultivation under study. 
Table 1: Area of crop cultivation

\begin{tabular}{|l|l|l|}
\hline Crops & Area in ropani & Area percent \\
\hline Paddy & 61.81 & 31.70 \\
\hline Wheat & 43.50 & 22.31 \\
\hline Maize & 34.00 & 17.44 \\
\hline Tomato & 15.00 & 7.69 \\
\hline Potato & 8.81 & 4.52 \\
\hline Beans & 4.06 & 2.08 \\
\hline Cauliflower & 3.19 & 1.63 \\
\hline Cabbage & 1.69 & 0.87 \\
\hline Radish & 1.69 & 0.87 \\
\hline Chilly & 1.50 & 0.77 \\
\hline Other & 19.75 & 10.13 \\
\hline Total & $\mathbf{1 9 4 . 9 9 7}$ & $\mathbf{1 0 0 . 0 0}$ \\
\hline Note: One Ropani is equal to 508.74 square metres & \\
\hline
\end{tabular}

Source: Field survey, 2014

When we briefly look at the cultivation of Godawari we see that maize is grown in 34 ropani of land which is $17.44 \%$ of the total cultivation. Potatoes are grown in 8.81 ropani of land which is $4.52 \%$ of the total cultivated land under study. Cauliflower is grown in 3.19 ropani which is $1.63 \%$ of the total land cultivation under study. Cabbage is grown in 1.69 ropanies of land which is $0.87 \%$ of the total cultivation under study. Radish is grown in 1.69 ropani of land which $.87 \%$ of the total cultivation under study. Chilly is grown in 1.50 ropani of land which is. $74 \%$ of the cultivated land. Other than mentioned crops are grown in 19.75 ropani of land which is $10.15 \%$ of the land under study.

Cropping area and farming households

Among total cultivated land vegetable occupies $18.43 \%$ of land. Out of total 30 surveyed households, only 16 households have vegetable production especially for 
commercial purpose. The distribution of the size of the land for vegetable cultivation of households is as follows:

Table 2: Households of vegetable cultivator and landholding size

\begin{tabular}{|l|l|l|}
\hline Area in ropani & Number of Household & Percent of $\mathbf{H H}$ \\
\hline Non & 14 & 46.7 \\
\hline Less than 0.25 & 5 & 16.7 \\
\hline 0.26 to 1.00 & 5 & 16.7 \\
\hline 1.00 to 2.00 & 3 & 10.0 \\
\hline More than 2.00 & 3 & 10.0 \\
\hline Total & $\mathbf{3 0}$ & $\mathbf{1 0 0 . 0}$ \\
\hline
\end{tabular}

Source: Field survey, 2014

From table 2 only 16 households cultivate vegetable for commercial purposes. More households have less than one ropani of land for vegetable cultivation and only six households have more than one ropani of land for it.

\section{Use of fertilizer}

Different types of chemical fertilizers are used in the study area. Major chemical fertilizers used for the improvement of crop production are urea, DAP and potash. Farmers use different types of chemical fertilizers for different crops. So, the following description presents the status of the use of fertilizer in the study area:

Urea: All households i.e. 13 households of wheat production use urea. Among 30 surveyed households in Godawari and Beshankhunarayan VDCs out of 17 maize growers 11 (64.71\%) households use urea. Out of 20 households that grow paddy, 19 (95\%) households use urea. Similarly, only two households grow tomato in which one household use urea and four households grow potato in which three of them use urea. Farmers use for crops like beans, cauliflower, cabbage, radish and chilly.

DAP: Proportion of DAP user farmers in the study area is lower than urea user. They use this fertilizer only for maize, paddy, wheat, potato. DAP is mostly used for paddy and potato. Other crops have very little use of DAP. From the table below, it is clear that DAP user farmers are very few and they use this fertilizer only in few crops which is very low proportion than urea. 
Potash: Potash is used mostly for vegetable production rather than in cereal crops like maize, wheat and paddy. Only one household of total 20 paddy farmer use potash and one household among 13 of wheat producer households. In total vegetable producer households are lower in numbers but the proportion of potash users seems higher.

Cow Dung: Cow dung is the major source of organic fertilizers in Nepalese agriculture. Compost is made from cow dung which is used to maintain soil fertility and organic matter of soil of agriculture field. However, very few farmers use cow dung making compost for their crop production in the study area. Only four households of out of total 17 households use compost of cow dung for maize cultivation and only one household of total 20 households of paddy farmer use this for their cultivation. Farmers use cow dung single time or for only one crop in a year. According to them it is sufficient for whole of the year. It is not only because of their belief of sufficiency for the year. It is because of the decreasing tradition of livestock ranching of the farmers. From the discussion with the farmer it was found that very few farmers keep their livestock so they have lack of compost for their cultivation.

\section{Use of pesticide and fertilizer}

From the surveyed 30 households, it was found that 24 households use pesticides and 14 households use external use fertilizer (vitamin). From the table 5, among 83 households 43 (51.81\%) households use pesticides and 15 households (18.07\%) use external use fertilizer for improvement of crop production. All of the vegetable cultivator uses pesticides except potato. However, five households out of 12 households of potato farmers use pesticides in potato crop. Similarly, six wheat farming households out of total thirteen households, nine out of 20 households of paddy farmer and two households out of 17 maize farmer households. External or injected fertilizers to promote crop production locally known as vitamins are used for maize, wheat and potato. All 12 households of potato farmer use vitamin in potato.

Table 3: Pesticides and fertilizer households

\begin{tabular}{|l|c|c|c|c|c|}
\hline \multicolumn{1}{|c|}{ Crops } & $\begin{array}{c}\text { Cultivated } \\
\text { HH }\end{array}$ & $\begin{array}{c}\text { Number } \\
\text { of pesticides } \\
\text { user HH }\end{array}$ & $\begin{array}{c}\text { HH \% of } \\
\text { pesticides } \\
\text { user }\end{array}$ & $\begin{array}{c}\text { Number of } \\
\text { fertilizer } \\
\text { user HH }\end{array}$ & $\begin{array}{c}\text { HH \% of } \\
\text { fertilizer } \\
\text { user }\end{array}$ \\
\hline Maize & 17 & 2 & 11.76 & 2 & 11.76 \\
\hline Paddy & 20 & 9 & 45.00 & 0 & 0.00 \\
\hline
\end{tabular}




\begin{tabular}{|l|c|c|c|c|c|}
\hline Beans & 4 & 4 & 100.00 & 0 & 0.00 \\
\hline Wheat & 13 & 6 & 46.15 & 1 & 7.69 \\
\hline Tomato & 3 & 3 & 100.00 & 0 & 0.00 \\
\hline Potato & 12 & 5 & 41.67 & 12 & 100.00 \\
\hline Cauliflower & 2 & 2 & 100.00 & 0 & 0.00 \\
\hline Cabbage & 2 & 2 & 100.00 & 0 & 0.00 \\
\hline Radish & 2 & 2 & 100.00 & 0 & 0.00 \\
\hline Chilly & 2 & 2 & 100.00 & 0 & 0.00 \\
\hline Others & 6 & 6 & 100.00 & 0 & 0.00 \\
\hline Total & $\mathbf{8 3}$ & $\mathbf{4 3}$ & $\mathbf{5 1 . 8 1}$ & $\mathbf{1 5}$ & $\mathbf{1 8 . 0 7}$ \\
\hline
\end{tabular}

Source: Field survey, 2014

Cereal crops such as maize, paddy and wheat have less use of pesticides than for vegetable farming. External use of fertilizer is mostly in potato only. Remaining maize and wheat have very little use of it.

\section{Tools and technique used during pesticides and fertilizer use in crops}

Among 24 households using pesticides for their farming, 8 of them use sprayer, 10 of them use manual pot, 7 of them use glove for protection, half of them use mask and other manual protection system are used by only seven households. It shows that proper technique and protection system using pesticides is lacking in the study area. Similarly, protection system and using system of vitamin user is also not proper. It indicates that possible health hazard due to improper using technique and protection system has caused health hazard of farmers in the study area. Use of pesticides and vitamin are related to human health in two aspects. Firstly, how much precaution they have adopted during using pesticides in their crops. From the quantitative data analysis, it was found that all farmers do not take better precaution on it. However, some of them are aware. Using manual pot for pesticides is higher possibility of exposure on the body of the farmer. Only $29.17 \%$ of the farmers use glove to make safe their hand with pesticides exposure. Only $50 \%$ of the farmers use mask means half of the farmers are not so aware in this context. However, some other farmers cover their face using their wearing cloth such as shawl. Secondly, its concern is related to amount of pesticides, duration of use and consumption which is directly related health of consumer. From the field survey, it was found that farmers are not aware about the consumer health. It was 
found that some farmers use pesticides even less than one-week duration selling to the market. It is difficult to measure how much effect on the health of the consumers because of the use of pesticides and fertilizers. They do not have basic information about using such pesticides and chemical fertilizers.

\section{Impact on human health}

Intensity and dimension of the impact of pesticides and fertilizers on human health is lacking in the study area. From the literature and practice of pesticides use in the study area, it can be concluded that there is no proper use of pesticides. However, some of the farmers express that they have experienced direct impact of pesticides on their health. Major health problems in the study area expressed by farmers are blood pressure, cough, fever, cold, joint pain, gastric, headache, diabetic, stomach pain and eye problem. Some of them have experienced headache, unhealthy feeling after frequent use of pesticides. Many people in study area suffer from cold, blood pressure, headaches etc. People have even stopped planting vegetables because of the diseases that infest the vegetables and grains. They do not want to use chemicals in their agriculture. People feel that the applying pesticides give them sickness. They complain about pesticides causing them nausea and burning sensation during application.

During the field study researchers entered a mustard field in Beshankhunarayan while Rogar was being applied and felt burning sensation on nostrils, eyes and mouth. So, some of the farmers have reduced for vegetables cultivation and some of them have completely abandoned due to this problem. So, systematic analysis and experiment of health hazard test is required to identify actual effect. Experienced farmers are aware about the health hazard of using pesticides but most of them have no alternative income source. So, they are doing vegetable farming and using pesticides. So, this study area apparently is not sufficient to expose us the hidden pain behind using chemical pesticides, fertilizer and vitamins. Incidental exposures to several persistent and non-persistent pesticides and their metabolites can be determined by analysis of serum, fat, urine, blood and breast milk. This study has no medical examination reports. This study can only take the words of the interviewees about the state of their health. In this case it all seems normal but we do not know the long-lasting effects of exposure to these chemicals used in household agriculture.

\section{Conclusion}

Research on the impact of use of chemical fertilizers and pesticides is very limited in Nepal. However, many news and events related to the exposure of these chemicals 
and their impacts are highlighted many times. Most of the farmers use chemical fertilizer such as urea, DAP and potash. Urea is mostly used for the cereal crops and some of the vegetable crops such as potato and tomato. DAP is also used for similar crops. Both DAP and urea are not used for green vegetables. Potash is used for most of the green vegetables rather than in cereal crops. Compost of cow dung uses is very limited. Very few numbers of farmers have compost of cow dung for their cultivated land. Compost of cow dung is used only for maize and paddy who have limited amount of it. So, it is mostly depended on chemical fertilizer. Farmers also use external booster of crops locally known as vitamin but this is mostly used for potato. A few households use for maize and wheat but it is very limited. The similar result was found in a few studies from elsewhere. Nepal (Diwakar et al. 2008). Pesticides are used for most of the vegetable's crops. Maize, paddy, wheat and potato have lower proportion of use than other crops. All farmers use pesticides for other crops than these cereal crops. Farmers use sprayer, manual pot, glove, mask and other manual tools and techniques during the use of pesticides. However, only limited farmers use these protection system and systematic use of pesticides which is general scenario in developing countries (Jallow, 2017). Principally, it seems hazardous for farmers. It is because of the lack of awareness. However, farmers have experienced health problem during the use of pesticides and a few abandoned cultivating commercial vegetables. Similar experience was also found in the vegetable farmers of Tarai in Nepal (Lamichhane et al. 2019).

Pesticides, fertilizers and vitamins are chemical compounds used in agriculture to improve the production. Pesticides are especially made chemical compositions for killing the pests such as insects, fungus, rodents, and herbs around the houses, schools, playgrounds and agricultural fields. These chemical compounds have high toxicity that destroys the unwanted insects, fungus, herbs and rodents. At the same time, the toxic compounds also harm the human health if exposed long enough. The effects can be of long term and short term. Long term effects are cancer, respiratory disorder and reproductive disorder while short term effects are irritation of the skin, irritation to the respiratory system, irritation of the eyes, etc. Even though the company claims that the products are safe and non-toxic. They are indeed toxic. Pesticides are very harmful to human beings. Though pesticides are especially made to attack particular pests they harm other fauna and flora which are useful to human beings. 


\section{References}

Bhandari, G. (2014). An overview of agrochemicals and their effects on environment in Nepal. Applied Ecology and Environmental Sciences, 2(2): 66-73.

Diwakar, J., Prasai, T., Pant, S. R. and Jayana, B. L. (2008). Study on major pesticides and fertilizers used in Nepal. Scientific World, 6(6): 76-80. doi: https:/ / doi.org/10.3126/sw.v6i6.2638

Ghimire, A. \& Khatiwada, B. P. (2001). Use of pesticides in commercial vegetable cultivation in Tandi Eastern Chitwan, Nepal. Chitwan: Rampur Nepal.

Jallow, M. F. A., Awadh, D. J., Albaho, M. S., Devi, V. Y. and Thomas, B. M. (2017). Pesticide knowledge and safety practices among farm workers in Kuwait: Results of a survey. International Journal of Environment Research on Public Health, 14(4): 340. doi: 10.3390/ijerph14040340.

Kumar, N., Pathera, A. K., Saini, P. and Kumar, M. (2012). Harmful effect of pesticides on human health. Annals of Agri-Bio Research, 17(2): 125-127.

Lamichhane, R., Lama, N., Subedi, S., Singh, S. B., Shah, R. B. and Yadav, B. K. (2019). Use of pesticides and health risk among farmers in Sunsari district, Nepal. Journal of Nepal Health Research Council, 17(1), 42: 66-70. DOI https://doi.org/10.33314/jnhrc.1204.

Sabur and Molla (2001). Pesticide use and its impact on crop production and evaluation of IPM technologies in Bangladesh. Bangladesh Journal Agriculture Economics, XXIV (1 \& 2): 21-38.

Sharma, D. R, Thapa, R. B., Manadhar, H. K., Shrestha, S. N. and Pradhan, S. B. (2012). Use of pesticides in Nepal and impacts on human health and environment. The Journal of Agriculture and Environment 13: 67-74.

Sharma, N and Singhvi, R. (2017). Effects of chemical fertilizers and pesticides on human health and environment: A review. International Journal of Agriculture, Environment and Biotechnology, 10(6): 675-679.

doi: 10.5958/2230-732X.2017.00083.3.

Stamata, P. N., Maipas, S., Kotampasi, C., Stamatis, P. and Hens, L. (2016). Chemical pesticides and human health: The urgent need for a new concept in agriculture. Frontiers in Public Health, 4:148. doi:

10.3389/fpubh.2016.00148

Tribe, D. (1994). Feeding and greening the world. Guildford: Biddles Ltd. 